\title{
Article
}

\section{Intelligent Control System of Internal Expansion over Bending and Calibration (IEOBC) Process for Large Pipe Ends}

\author{
Ruixue Zhai ${ }^{1,2}$, Zhaoxu Jiao ${ }^{1,2}$, Yashuai Han ${ }^{1,2}$, Jun Zhao ${ }^{1,2}$ and Gaochao Yu ${ }^{1,2, *(1)}$ \\ 1 Key Laboratory of Advanced Forging \& Stamping Technology and Science, Yanshan University, Ministry of \\ Education of China, Qinhuangdao 066004, China; zhairuixue@ysu.edu.cn (R.Z.); 17743775316@163.com (Z.J.); \\ 18233586438@163.com (Y.H.); zhaojun@ysu.edu.cn (J.Z.) \\ 2 College of Mechanical Engineering, Yanshan University, Qinhuangdao 066004, China \\ * Correspondence: gch_yu@ysu.edu.cn
}

check for updates

Citation: Zhai, R.; Jiao, Z.; Han, Y.; Zhao, J.; Yu, G. Intelligent Control System of Internal Expansion over Bending and Calibration (IEOBC) Process for Large Pipe Ends. Symmetry 2021, 13, 1618. https:// doi.org/10.3390/sym13091618

Academic Editor: Sergei Alexandrov

Received: 11 August 2021

Accepted: 30 August 2021

Published: 3 September 2021

Publisher's Note: MDPI stays neutral with regard to jurisdictional claims in published maps and institutional affiliations.

Copyright: (c) 2021 by the authors. Licensee MDPI, Basel, Switzerland. This article is an open access article distributed under the terms and conditions of the Creative Commons Attribution (CC BY) license (https:// creativecommons.org/licenses/by/ $4.0 /)$.

\begin{abstract}
The flattening and asymmetry of a pipe end section seriously affects the welding quality between pipes, therefore the calibration process for pipe end to improve roundness is essential. Because the calibration for a pipe end involves local elastic-plastic deformation for the end effect, it is still difficult to establish an accurate theoretical model. The reasonable and intelligent control method is nevertheless an effective means to improve the production efficiency. In this paper, an internal expansion over bending and calibration (IEOBC) process is introduced. According to the characteristics of the process, the structure of the mobile intelligent calibration machine for large pipe ends is designed, and the intelligent control hardware system of the machine is built. Based on the LabVIEW software platform, an intelligent control software system for the IEOBC process is developed. A three-step control strategy is combined with pipe size detection and ovality recognition. The intelligent prediction and execution of the calibration process parameters are realized. The experimental results show that the intelligent control system has good stability and accuracy, and the ovality can be controlled within $0.5 \%$.
\end{abstract}

Keywords: large pipe; internal expansion; over bending and calibration; intelligent control system; ovality

\section{Introduction}

With the transfer of oil and gas development to unconventional oil and gas resources because of the remote and increasingly harsh development environments, more requirements for pipeline construction are being put forward. The ovality of the pipe body or end are an important index to measure the quality of pipe fittings. According to API Spec 5L standard [1], the ovality of pipe body should not exceed $1.0 \%$. Because the ovality of the pipe end exceeding the standard not only affects the welding quality of the pipe fittings and pipeline safety, but also limits the use of automatic welding machines and reduces the efficiency of pipeline laying, the requirement of pipe end ovality is stricter than that of pipe body.

The calibration process for large pipes mainly includes the expansion or compression and setting round process, over-bending setting round process, and the three-roller setting round process. In the production of longitudinally submerged arc welding (LASW) pipes, the calibration process is generally used to calibrate the pipe by expansion or compression. The expansion process can not only correct the ovality of the pipe, but also improve the strength of the pipe and reduce residual stress. Karrech et al. [2] established a theoretical model to predict the stress distribution in both the deformation zone and the forming force. Yin et al. [3] studied the springback in the expansion process for forming LASW pipes. Ren et al. [4] analyzed the expansion process in the UOE forming process through a numerical simulation and proved that the expansion can make the distribution of residual stress more 
uniform. Herynk et al. [5] studied the UOE and UOC processes through numerical simulations, and presented that compression, instead of expansion, can significantly improve the collapse performance. Yin et al. [6] analyzed the compression process and Yu et al. [7] adjusted the roundness of the elbow with the compression mode in a cold stamping process for forming single-welded elbows. They proved that the roundness of the pipe can be improved by compression. Expansion or compression could make the circumference of a pipe become longer or shorter, respectively. When the circumference is qualified, the expansion or compression is no longer applied [8].

He et al. [9] and Wang et al. [10] respectively studied the external holding type, internal supporting type, and setting round process for pressure vessels, and gave the appropriate die parameters and process parameters. Yu et al. established the mechanical model and springback analytical model for the symmetrical three-roller setting round process through an upper roller built-in $[8,11]$ and an upper roller built-out $[12,13]$, allowing them to obtain the curvature distribution and historical changes and realize the optimization of process parameters and the prediction of reduction. Then, Yu et al. [14,15] developed the process of a continuous and synchronous calibration of roundness and straightness with three rollers, and carried out research on theoretical analysis, numerical simulation, and roller design. In order to reduce the ovality of pipes applied in the deep sea and ultra-deep sea, and to improve their compressive strength, a two-roller continuous calibration (TRCC) process by compression was proposed [16]. The above two processes are only suitable for the calibration of a full-length pipe.

Based on the above, an over-bending setting round process for pipe-end of large pipes by mould press is widely used by large pipe manufacturers. The process has the advantages of simple operation and high efficiency, using the same group of dies to complete the round correction of various specifications of pipe. Zhan et al. established both a two-step control strategy $[17,18]$ and a three-step control strategy [19]; however, the method relies on large press, with which it is difficult to meet the new requirements of flexible cablication in construction sites. Therefore, the major production enterprises are in urgent need of a kind of calibration equipment for large pipe ends which is easy to move and has high automation and a high intelligent level.

The structure of the equipment required for the internal expansion over bending and calibration (IEOBC) process for large pipe ends is simple, and it is easy to realize the motorized field operation. In this paper, an internal expansion over-bending and calibration process is introduced. According to the characteristics of the process, the structure of the mobile intelligent calibration machine for large pipe ends is designed, and the intelligent control hardware system of the machine is built. Based on the LabVIEW software platform, an intelligent control software system for IEOBC process is developed. The three-step control strategy is combined with pipe size detection and ovality recognition. The intelligent prediction and execution of the calibration process parameters are realized.

\section{IEOBC Process}

The principle of the IEOBC process is shown in Figure 1. Two petal dies with an $X$-axis symmetric distribution and a radius less than that of the pipe are used to move in the direction of the short axis of the pipe, and the pipe is expanded from the inside to the outside. In this process, the curvature of point $A$ and its adjacent region increases continuously, resulting in the same direction-bending deformation. The curvature radius of point $\mathrm{B}$ and its adjacent region decreases continuously, resulting in reverse-bending deformation. The cross-section of the pipe is formed from the initial transverse ellipse shape about two axisymmetries to the longitudinal ellipse shape about two axisymmetries, and it becomes a circular section with any axisymmetric curves after springback. This process is called internal expansion over bending calibration process. 


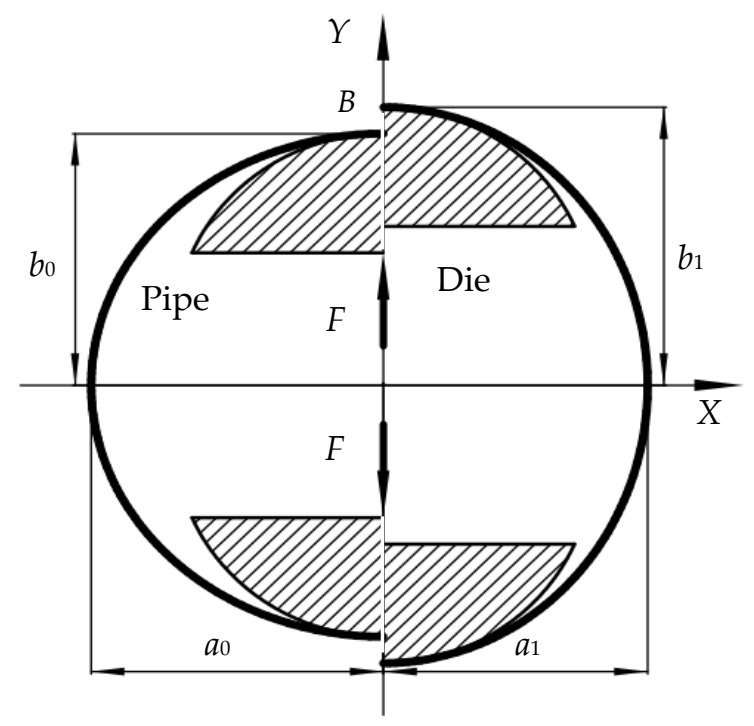

Figure 1. IEOBC process: $a_{0}$ is the length of major axis before deformation; $b_{0}$ is the length of minor axis before deformation; $a_{1}$ is the length of major axis after deformation; $b_{1}$ is the length of minor axis after deformation; $F$ is the force.

\section{Control Principle}

The control system mainly includes four elements: real-time monitoring, real-time identification, real-time prediction, and real-time control. Based on the laser sensing technology and automatic control technology, the intelligent control system of the IEOBC process is established. The principle is shown in Figure 2.

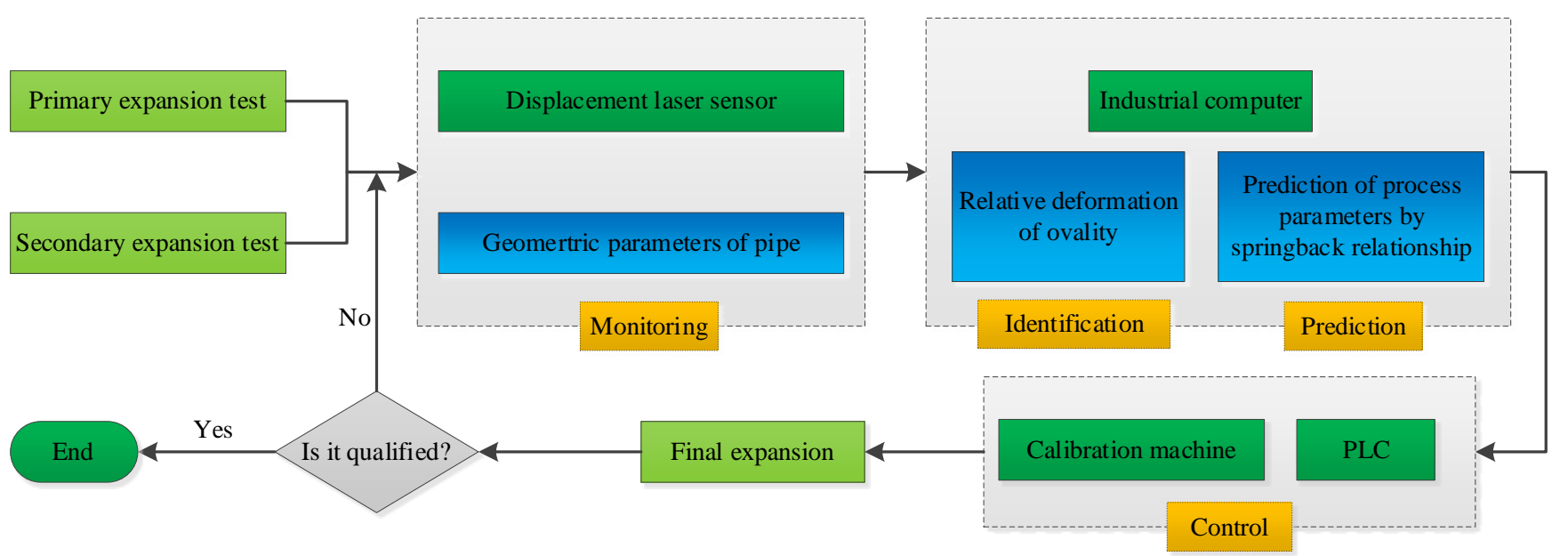

Figure 2. Schematic diagram of intelligent control.

The control process can be divided into three steps:

(1) The initial ovality of the pipe is detected;

(2) The primary expansion and secondary expansion tests are carried out, the relative deformation and ovality after expansion of the two expansion tests are recorded, and the process parameters of the final internal expansion pipe fittings are predicted according to the linear relationship [18,19];

(3) The calibration machine automatically executes the above process parameters. After final expansion, the ovality of the pipe fittings should be detected again. If the accuracy is qualified, the program will be terminated; If the accuracy is unqualified, further correct the linear relationship according to the final expansion data, and repeat the above steps until its ovality meets the accuracy requirements. 


\section{Hardware System}

The hardware system mainly includes a calibration machine body, control device, laser-detection device, and some auxiliary hardware. As shown in Figure 3, the selfdeveloped mobile intelligent calibration machine for large pipe fittings is presented, and its main technical parameters are shown in Table 1.

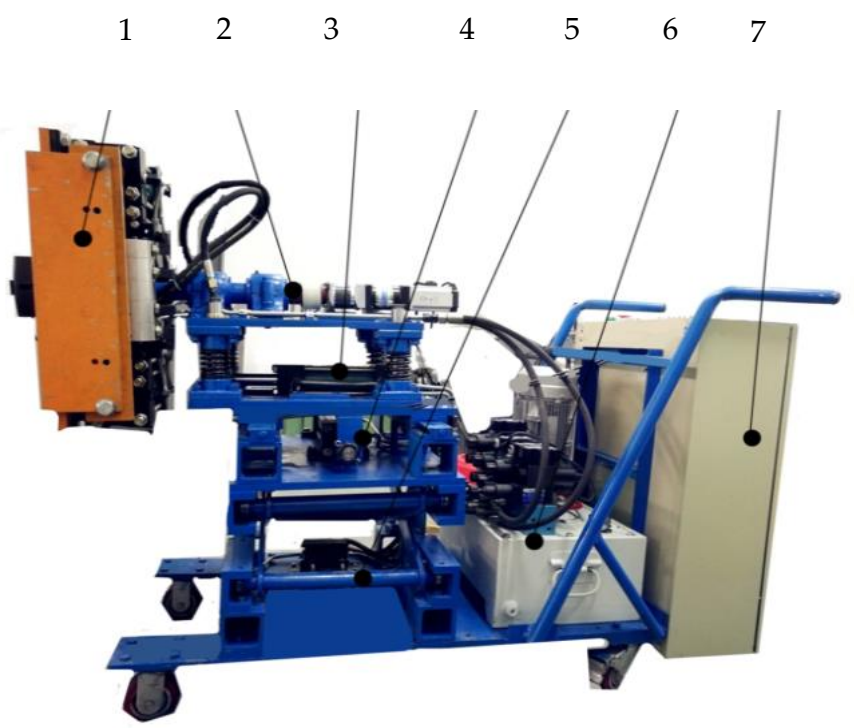

Figure 3. Self-developed mobile intelligent calibration machine: 1 . Calibration device; 2 . Rotating device; 3. Positioning device of Y-direction; 4. Positioning device of X-direction; 5. Positioning device of Z-direction; 6. Hydraulic station; 7. Electric control panel.

Table 1. Main technical parameters.

\begin{tabular}{cc}
\hline Parameters & Value \\
\hline Hydraulic cylinder stroke $/ \mathrm{mm}$ & 70 \\
Maximum working pressure/MPa & 14 \\
X-direction travel/mm & 300 \\
Y-direction travel/mm & 100 \\
Z-direction travel/mm & 200 \\
Rated torque of rotating device $/ \mathrm{N} \cdot \mathrm{m}$ & 65 \\
Pipe diameter range $/ \mathrm{mm}$ & $380-1070$ \\
Overall dimensions of calibration machine $/ \mathrm{mm}$ & $1300 \times 600 \times 1100$ \\
\hline
\end{tabular}

\section{Software System}

Based on programmable logic computer (PLC) and LabVIEW graphic language, an intelligent control software system is established, which mainly includes a communication module, geometric feature identification module, and calibration strategy module.

\subsection{Communication Module}

The control system uses the industrial computer as a host computer and a PLC as the lower computer. Through the communication among the industrial computer, the PLC, and the laser displacement sensor, the control of each executive part is realized, as shown in Figure 4.

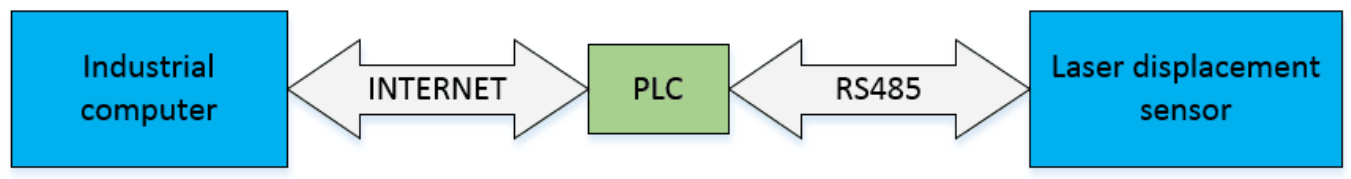

Figure 4. Communication between hardware. 


\subsection{Geometric Feature Identification}

In actual production, the geometric shape of the pipe end section is generally approximated as an ellipse, and the identification of its geometric feature can be divided into the following two steps:

(1) Identify and locate the center of the ellipse: the three-step successive approximation center positioning method is adopted, and its process is shown in Figure 5. The two sensors are arranged in opposite directions. Firstly, the two sensors are turned to the vertical direction, and the Z-direction positioning device is adjusted to make the readings of the two sensors the same. Secondly, the two sensors are turned to the horizontal direction, and the X-direction positioning device is adjusted to make the readings of the two sensors the same. The above steps are repeated twice.

(2) Identify and locate the major and minor axis position of ellipse: the calibration device rotates $180^{\circ}$. Meanwhile, two displacement sensors are used to measure the inner wall of the whole pipe, the location and the length of the major axis and minor axis is recorded, and the ovality is calculated. By rotating the calibration device, when the difference between the real-time inner diameter Dr and the minimum inner diameter Dmin reaches the preset accuracy $\xi$, where is the position of the minimum diameter of ellipse. The process is shown in Figure 6.

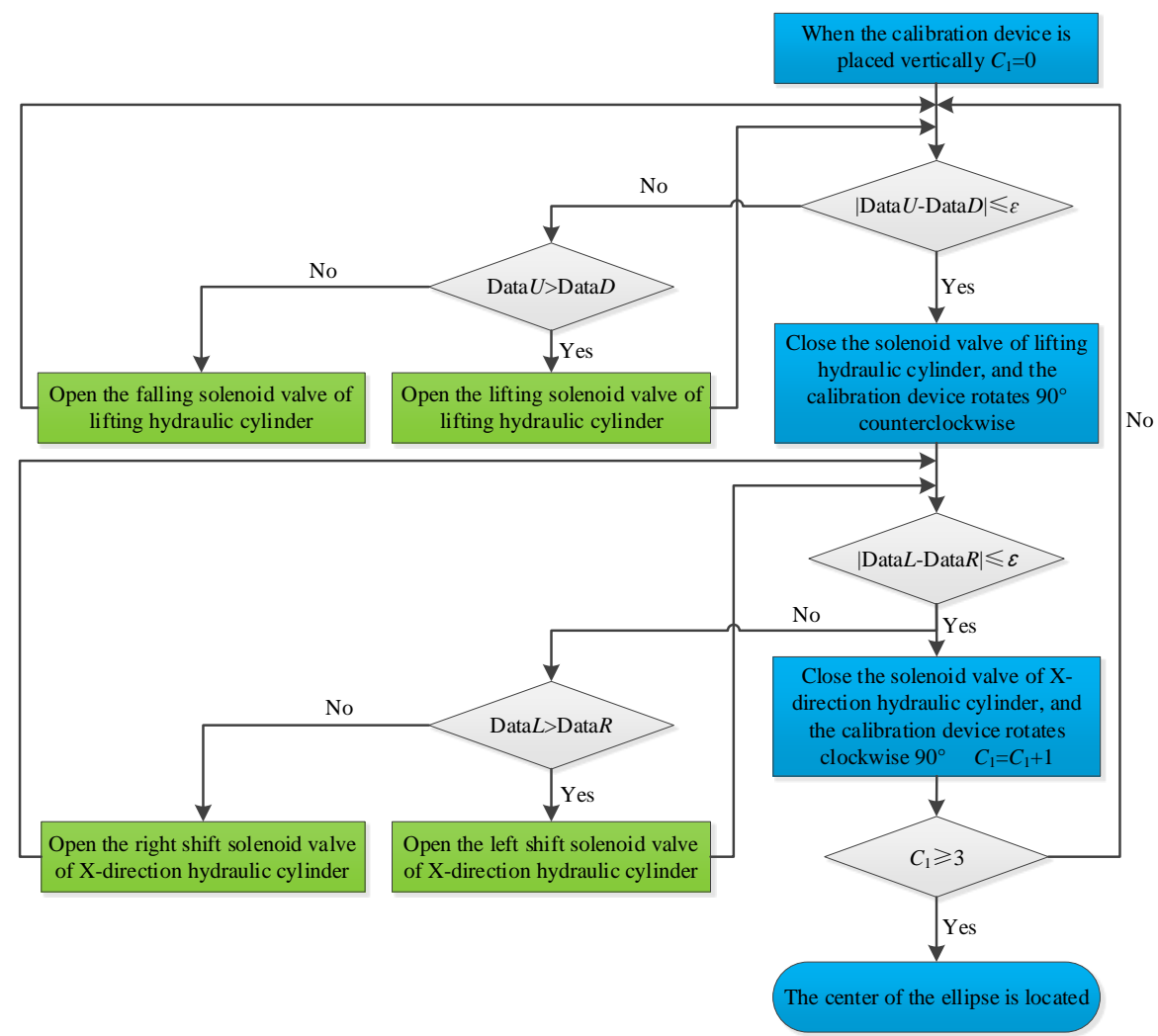

Figure 5. Flow chart illustrating the identification and location of the ellipse center: $C_{1}$ and $C_{2}$ are counters, respectively; $U$ and $D$ are the degrees of the two sensors when the two displacement laser sensors are placed in the vertical direction; $L$ and $R$ are the degrees of the two sensors when the two displacement laser sensors are placed in the horizontal direction. 


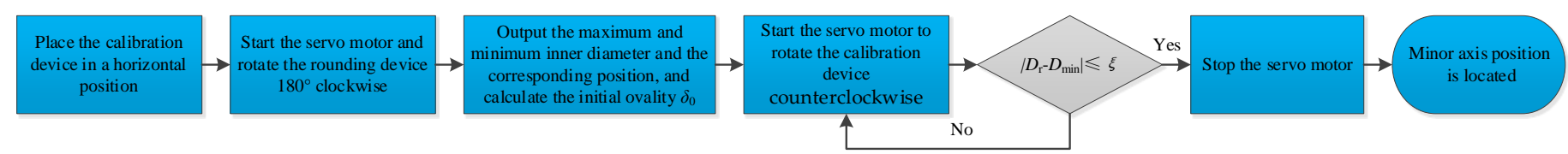

Figure 6. Flow chart of detection and positioning of ellipse.

\subsection{Calibration Strategy Module}

According to the approximate linear relationship between the relative deformation and the ovality after unloading $[18,19]$, the calibration strategy is formulated as follows:

(1) The initial ovality of the pipe is detected, and the circumference of the pipe is calculated by Equation (1) and Equation (2) [20].

$$
\begin{gathered}
l \approx \pi(a+b)\left(1+\frac{\gamma^{2}}{4}+\frac{\gamma^{4}}{64}\right) \\
\gamma=\frac{a-b}{a+b}
\end{gathered}
$$

where, $l$ is the circumference of the pipe, $a$ is the length of major axis, $b$ is the length of minor axis.

(2) Two expansion tests. The relative deformation of $H_{1}$ and $H_{2}$ after loading and the length of the major axis $a$ and the length of minor axis $b$ after unloading are recorded in each expansion test. The ovality $\delta_{1}$ and $\delta_{2}$ are calculate by Equation (3). The relative deformation of $\mathrm{H}_{3}$ is required and calculated for final calibration by Equation (4).

$$
\begin{gathered}
\delta=\frac{a-b}{D} \times 100 \% \\
H_{3}=\frac{\left(H_{2}-H_{1}\right) \delta_{2}}{\delta_{1}-\delta_{2}}+H_{2}
\end{gathered}
$$

where, $D$ is the nominal inner diameter.

(3) Final expansion.

If the ovality does not meet the requirements after the final expansion, the above steps are repeated until the ovality meets the requirements.

\section{Experimental Design}

In order to verify the reliability of the prototype and the intelligent control system of the intelligent calibration machine for large pipe fittings, the calibration experiments are carried out on an L50 and L1000 pipe, respectively. The geometrical parameters of the pipes are shown in Table 2, and the process parameters of the calibration die are shown in Table 3 . The ovality of each pipe is measured by using a three coordinate machine, and the results are compared with those of the calibration machine. The IEOBC experiments are shown in Figure 7.

Table 2. Geometrical parameters of pipe ( $\mathrm{mm})$.

\begin{tabular}{cccc}
\hline Pipes & Nominal Inner Diameter $\boldsymbol{D}$ & Wall Thickness $\boldsymbol{t}$ & Length $\boldsymbol{L}$ \\
\hline L50 & 400 & 6 & 50 \\
L1000 & & & 1000 \\
\hline
\end{tabular}

Table 3. Process parameters of the calibration die ( $\mathrm{mm})$.

\begin{tabular}{cccc}
\hline Radius & Thickness & Width & End Fillet \\
\hline 150 & 50 & 150 & 6 \\
\hline
\end{tabular}



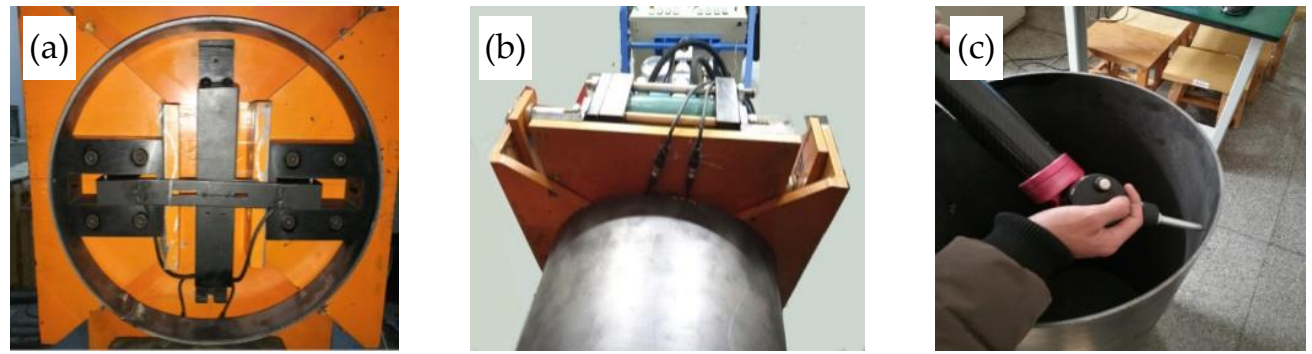

Figure 7. IEOBC experiments: (a) Calibration of whole pipe, (b) calibration of pipe end, (c) detection of pipes.

\section{Results and Discussion}

\subsection{Ovality Identification}

The comparison of ovality detection data between the calibration machine and the three coordinate machine is shown in Table 4. It can be seen from the table that the ovality identified by the calibration machine is consistent with that from the three coordinate machine, and the maximum deviation of ovality between the two is $0.24 \%$.

Table 4. Comparison of ovality detection data.

\begin{tabular}{ccccc}
\hline Detection Mode & \multicolumn{4}{c}{ Ovality $\delta / \%$} \\
\hline Calibration machine & 1.33 & 1.10 & 1.14 & 5.84 \\
Three coordinate machine & 1.56 & 1.21 & 1.38 & 5.95 \\
\hline
\end{tabular}

\subsection{Calibration Experiments}

The relationship between relative deformation and ovality after calibration is shown in Figure 8. It can be seen that the relationship between the relative deformation and the ovality after calibration is linear for the L50 pipe with an initial ovality of $5.8 \%$ and the L1000 pipe with an initial ovality of $8.6 \%$, which proves the feasibility of using the linear relationship as the control strategy of calibration for the whole pipe and pipe end.

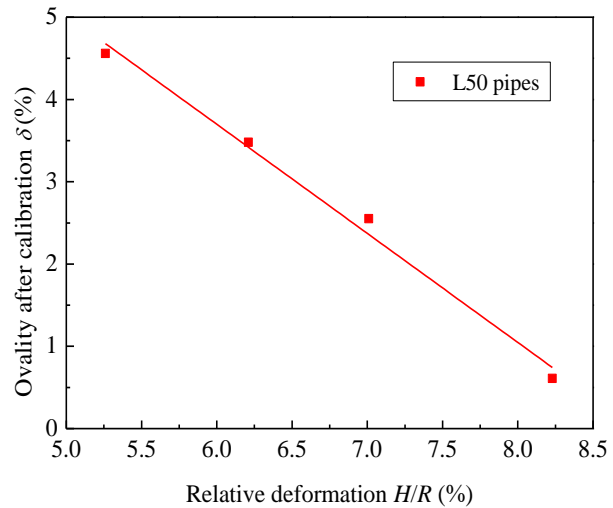

(a)

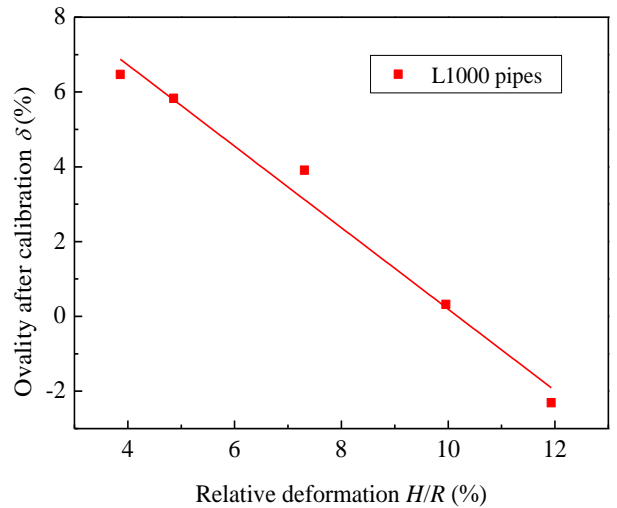

(b)

Figure 8. Relationship curve of relative deformation and ovality after unloading: (a) L50, (b) L1000.

The experimental results of the L1000 pipe by a three-step calibration method are shown in Table 5. It can be seen that the ovality of L1000 pipes with an initial ovality of $2.31 \%$ and $2.69 \%$ is $0.18 \%$ and $-0.31 \%$, respectively, after calibration, which meets the requirements for engineering precision [1]. The comparison of pipe before and after calibration is shown in Figure 9. The relative deformation of the final expansion is different from the predicted process parameters due to the error of displacement control of the hydraulic cylinder. 
Table 5. Experimental results of L1000 pipe by three-step calibration method.

\begin{tabular}{|c|c|c|c|}
\hline Pipe Number & Conditions & Relative Deformation $H / R(\%)$ & $\begin{array}{c}\text { Ovality } \\
\delta / \%\end{array}$ \\
\hline \multirow{5}{*}{ No.1 } & Initial & - & 2.31 \\
\hline & Primary expansion test & 1.94 & 1.67 \\
\hline & Secondary expansion test & 3.10 & 1.18 \\
\hline & Predicted process parameters & 5.54 & - \\
\hline & Final expansion & 5.73 & 0.18 \\
\hline \multirow{5}{*}{ No.2 } & Initial & - & 2.69 \\
\hline & Primary expansion test & 2.16 & 1.73 \\
\hline & Secondary expansion test & 3.27 & 1.24 \\
\hline & Predicted process parameters & 6.08 & - \\
\hline & Final expansion & 6.22 & -0.31 \\
\hline
\end{tabular}
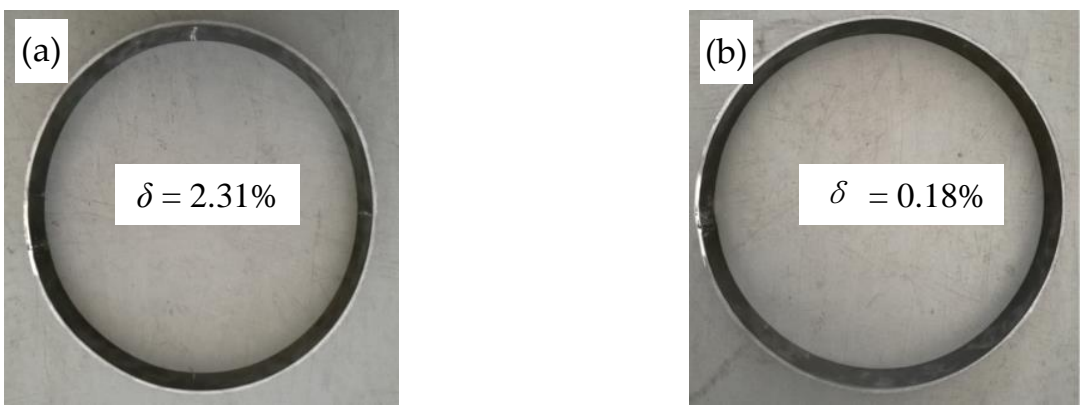

Figure 9. Comparison of pipes before and after calibration: (a) Before calibration, (b) after calibration.

\section{Conclusions}

(1) According to the characteristics of the IEOBC process for large pipe ends, the body structure of a mobile large pipe end calibration machine is designed, and the intelligent control hardware system of a calibration machine is built.

(2) Based on LabVIEW software platform, an intelligent control software system for a large pipe end calibration process is developed, which combines pipe size detection, ovality recognition, and a three-step control strategy to realize the intelligent prediction and execution of calibration process parameters.

(3) A large pipe end calibration machine with internal expansion is developed. The calibration experiments show that the intelligent control system of the calibration process with internal expansion has good stability and precision, and that the ovality of the pipe after calibration is within $0.5 \%$.

Author Contributions: Conceptualization, R.Z. and G.Y.; Formal analysis, Y.H.; Methodology, R.Z. and G.Y.; Software, R.Z.; Supervision, G.Y.; Validation, Z.J. and Y.H.; Writing-original draft, R.Z. and Z.J.; Writing-review and editing, J.Z. and G.Y. All authors have read and agreed to the published version of the manuscript.

Funding: This project was funded and supported by the National Natural Science Foundation of China (52005431 and 51705449), and Natural Science Foundation of Hebei province (E2020203086).

Institutional Review Board Statement: Not applicable.

Informed Consent Statement: Not applicable.

Data Availability Statement: Not applicable.

Conflicts of Interest: The authors declare no conflict of interest. 


\section{References}

1. American Petroleum Institute. Ansi/Api Specification 5L, Specification for Line Pipe, 45th ed.; American Petroleum Institute: Washington, DC, USA, 2012.

2. Karrech, A.; Seibi, A. Analytical model for the expansion of tubes under tension. J. Mater. Process. Tech. 2010, 210, 356-362. [CrossRef]

3. Yin, J.; Zhao, J.; Qu, X.Y.; Zhai, R.X. Springback Analysis of expanding and setting round for large diameter pipe. China Mech. Eng. 2011, 47, 32-42. [CrossRef]

4. Ren, Q.; Zou, T.X.; Li, D.Y.; Tang, D.; Peng, Y.H. Numerical study on the X80 UOE pipe forming process. J. Mater. Process. Technol. 2015, 215, 264-277. [CrossRef]

5. Herynk, M.D.; Kyriakides, S.; Onoufriou, A.; Yun, H.D. Effects of the UOE/UOC pipe manufacturing processes on pipe collapse pressure. Int. J. Mech. Sci. 2007, 49, 533-553. [CrossRef]

6. Yin, J.; Zhao, J.; Sun, H.L.; Zhan, P.P. Precise compression and setting round by mold for large pipes. Opt. Precis. Eng. 2011, 19, 2072-2078. [CrossRef]

7. Yu, G.C.; Zhao, J.; Wang, C.G.; Zhai, R.X.; Ma, R. Development of a cold stamping process for forming single-welded elbows. Int. J. Adv. Manuf. Technol. 2017, 88, 1911-1921. [CrossRef]

8. Yu, G.C.; Zhao, J.; Zhai, R.X.; Ma, R.; Wang, C.G. Theoretical analysis and experimental investigations on the symmetrical three-roller setting round process. Int. J. Adv. Manuf. Technol. 2018, 94, 45-56. [CrossRef]

9. He, Y.L.; Qiao, J.X.; Jia, C.D. The circularization technique for welded pipes. Welded Pipe Tube 1998, 21, $20-23$.

10. Wan, G.R. The design and application of rounding moulds for pressure vessels. Press. Vessel Technol. 1991, 6, 40-44.

11. Zhao, J.; Yu, G.C.; Ma, R. A mechanical model of symmetrical three-roller setting round process: The static bending stage. J. Mater. Process. Technol. 2016, 231, 501-512. [CrossRef]

12. Huang, X.Y.; Yu, G.C.; Zhao, J.; Mu, Z.K.; Zhang, Z.Y.; Ma, R. Numerical simulation and experimental investigations on a three-roller setting round process for thin-walled pipes. Int. J. Adv. Manuf. Technol. 2020, 107, 355-369. [CrossRef]

13. Huang, X.Y.; Zhao, J.; Yu, G.C.; Meng, Q.D.; Mu, Z.K.; Zhai, R.X. Three-roller continuous setting round process for longitudinally submerged arc welding pipes. Trans. Nonferr. Met. Soc. 2021, 31, 1411-1426. [CrossRef]

14. Huang, X.Y.; Yu, G.C.; Zhai, R.X.; Ma, R.; Zhou, C.; Gao, C.L.; Zhao, J. Roller design and numerical simulation of three-roller continuous and synchronous adjusting straightness and roundness process on LSAW pipes. China Mech. Eng. 2021, 57, 148-159. [CrossRef]

15. Huang, X.Y.; Yu, G.C.; Sun, H.L.; Zhao, J. A mechanical model of axial and circumferential bidirectional deformation for large thin-walled pipes in the process of continuous and synchronous calibration of roundness and straightness by three rollers. Int. J. Adv. Manuf. Technol. 2021. [CrossRef]

16. Peng, D.P.; Gong, Z.W.; Zhang, S.M.; Yu, G.C. Research on two-roller continuous calibration process by compression for submarine pipelines. Symmetry 2021, 13, 1224. [CrossRef]

17. Zhao, J.; Zhan, P.P.; Ma, R.; Zhai, R.X. Prediction and control of springback in setting round process for pipe-end of large pipe. Int. J. Pres. Vessel Pip. 2014, 116, 56-64. [CrossRef]

18. Zhao, J.; Zhan, P.P.; Ma, R.; Zhai, R.X. Control strategy of over-bending setting round for pipe-end of large pipes by mould press type method. Trans. Nonferr. Met. Soc. 2012, 22, 329-334. [CrossRef]

19. Zhan, P.P.; Zhao, J.; Li, P.; Shang, J.H. Three steps control strategy of over-bending setting round for pipe-end of large pipes. Mater. Sci. Technol. 2014, 22, 97-103.

20. Ivory, J. A new series for the rectification of the ellipsis. Trans. R. Soc. Edinb. 1796, 4, 177-190. [CrossRef] 